\title{
Pemberdayaan Masyarakat dalam Perencanaan Pasar Tradisional Terapung di Desa Bulucindea, Kecamatan Bungoro, Kabupaten Pangkajene dan Kepulauan
}

\author{
Imriyanti ${ }^{1}$, Rahmi Amin Ishak, Triyatni Martosenjoyo, Syarif Beddu, \\ M. Syavir Latif, Victor Sampebulu, Nasruddin, Hartawan, Dahri Kuddu, Pratiwi Mushar \\ Departemen Arsitektur, Fak. Teknik, Universitas Hasanuddin ${ }^{1}$ \\ imrianti@gmail.com ${ }^{1}$
}

\begin{abstract}
Abstrak
Desa Bulucindea memiliki potensi wisata hutan mangrove yang merupakan daerah konservasi pesisir di Kabupaten Pangkajene dan Kepulauan (Pangkep). Sebagai bagian dari pengembangan kawasan tersebut sesuai masterplan wilayah, ditetapkan 3 zona utama, yaitu zona hutan mangrove untuk kawasan konservasi lingkungan, zona sarana transportasi laut untuk dermaga, dan zona ekonomi untuk pasar tradisional. Perencanaan pasar tradisional di Desa Bulucindea disesuaikan dengan kondisi lingkungan fisik lokasi sebagai wilayah konservasi mangrove yang harus menjaga keberlanjutan lingkungan. Guna meningkatkan perekonomian daerah, perencanaan juga didasarkan pada kebutuhan masyarakat setempat. Dengan demikian permasalahan utama lokasi adalah bagaimana merencanakan fasilitas pasar tradisional di kawasan pesisir yang adaptif terhadap lingkungan dan kebutuhan ekonomi masyarakat. Berdasarkan pertimbangan tersebut, maka dilaksanakan kegiatan pengabdian pada masyarakat, melalui pemberdayaan dan sosialisasi kepada masyarakat dalam tahap perencanaan dan perancangan pasar tradisional di Desa Bulucindea. Tahap kegiatan mencakup analisis permasalahan melalui pengamatan terhadap kondisi lingkungan, dan melaksanakan FGD serta sosialisasi untuk mendapatkan input dari masyarakat terkait perencanaan pasar tradisional yang sesuai kebutuhan masyarakat dan kondisi fisik lingkungan pesisir pantai Desa Bulucindea. Dari kegiatan pengabdian masyarakat tersebut, konsep perencanaan yang dianggap sesuai untuk wilayah pesisir Desa Bulucindea adalah konsep "Pasar Tradisional Terapung". Perencanaan pasar tradisional tersebut telah dilaksanakan dan disosialisasikan kepada masyarakat Desa Bulucindea, sehingga dapat mewadahi kegiatan ekonomi masyarakat tanpa merusak habitat alami lingkungan setempat. Dengan kegiatan pengabdian masyarakat ini, masyarakat turut aktif dalam menjaga kelestarian hutan mangrove yang ada di pesisir Desa Bulucindea.
\end{abstract}

Kata Kunci: Pemberdayaan masyarakat; perencanaan; pasar tradisional; pesisir pantai; terapung.

\begin{abstract}
Bulucindea Village has the potential of mangrove forest tourism which is a coastal conservation area in Pangkajene and Kepulauan Regency (Pangkep). As part of the development of the area, three main zones were determined in the master plan, namely the zone of mangrove forests for environmental conservation, the zone of sea transportation facilities for docks, and the economic zone for traditional markets. Traditional market planning in Bulucindea Village is adapted to the physical condition of the location as a mangrove conservation area that must maintain environmental sustainability. To improve the regional economy, planning is also based on the needs of the local community. Thus the main problem of location is how to plan traditional market facilities in coastal areas that are adaptive to the environment and the economic needs of the community. Based on these considerations, community service activities are carried out, through empowerment and socialization to the community in the planning and design of traditional markets in the Bulucindea Village. The activity phase includes the analysis of problems through observing environmental conditions, and carrying out FGDs and socialization to obtain input from the community related to traditional market planning that suits community needs and the physical condition of the coastal environment of Bulucindea Village. From the community service activities, the planning concept that is considered appropriate for the coastal area of the Bulucindea Village is the concept of "Floating Traditional Market". The traditional market planning has been implemented and socialized to the people of Bulucindea Village, so that it can facilitate the economic activities of the community without damaging the natural habitat of the local environment.
\end{abstract}


With this community service activity, the community is actively involved in preserving the mangrove forests on the coast of Bulucindea Village.

Keywords: Community empowerment; planning; traditional markets; coastal; floating.

\section{Pendahuluan}

Desa Bulucindea dikembangkan sebagai kawasan wisata mangrove yang didukung oleh kegiatan ekonomi masyarakat nelayan. Untuk mendukung konservasi kawasan mangrove, pemerintah setempat telah mencanangkan peraturan desa terkait kewajiban menanam bibit mangrove, dan menjaga kebersihan lingkungan kawasan tersebut. Daya tarik kawasan wisata mangrove sebagai kawasan konservasi serta menjadi spot selfie dan grufie bagi masyarakat, telah mendorong pertumbuhan ekonomi masyarakat setempat. Keberadaan kegiatan ekonomi di kawasan wisata mangrove Desa Bulucindea sebagai bagian dari kegiatan wisata seringkali berdampak buruk bagi kualitas lingkungan di kawasan mangrove. Kurangnya kesadaran masyarakat akan kebersihan lingkungan, cenderung menyebabkan rusaknya habitat alami tanaman mangrove. Dalam upaya menjaga keberlanjutan kawasan wisata mangrove di Desa Bulucindea, maka pelibatan masyarakat dalam pengelolaaan kawasan wisata selain sebagai sumber mata pencarian baru bagi masyarakat setempat, juga mengarahkan masyarakat untuk menjaga kelestarian kawasan tersebut.

Perencanaan pasar tradisional di Desa Bulucindea untuk mewadahi kegiatan ekonomi masyarakat, disesuaikan dengan kondisi lingkungan fisik lokasi sebagai wilayah konservasi mangrove yang harus menjaga keberlanjutan lingkungan. Masterplan wilayah tersebut di bagi 3 zona, yaitu zona hutan mangrove berupa kawasan konservasi lingkungan, zona sarana transportasi laut berupa dermaga, dan zona ekonomi berupa pasar tradisional. Wilayah pesisir pantai di Desa Bulucindea dijadikan pengembangan zona ekonomi untuk pasar tradisional. Guna meningkatkan perekonomian daerah, perencanaan juga didasarkan pada kebutuhan masyarakat setempat, kondisi fisik lingkungan dan standar perencanaan pasar tradisional.

Berdasarkan kebutuhan masyarakat untuk perwadahan kegiatan ekonomi dan konservasi kawasan pesisir, maka konsep perencanaan pasar tradisional di Desa Bulucindea yang sesuai adalah "Pasar tradisional terapung". Kondisi alam lokasi perencanaan pasar tradisional terapung di wilayah pesisir pantai. Pesisir pantai dibedakan dua lokasi yaitu pesisir pantai di atas air dan transisi antara air dan darat. Pasar tradisional adalah pasar yang dikelola dengan manajemen yang lebih tradisional dan simpel daripada pasar modern, sedangkan pasar terapung adalah sebutan untuk sarana jual beli yang terletak di atas perairan.

\section{Latar Belakang Teori}

\subsection{Pasar Tradisional}

Pasar tradisional adalah pasar yang dikelola dengan manajemen yang lebih tradisional dan simpel daripada pasar modern, umumnya pasar tradisional tersebut terdapat di pinggiran perkotaan/jalan atau lingkungan perumahan. Menurut Peraturan Presiden RI No. 112 Tahun 2007, pasar tradisional adalah pasar yang dibangun dan dikelola oleh Pemerintah, Pemerintah Daerah, Swasta, Badan Usaha Milik Negara dan Badan Usaha Milik Daerah termasuk kerjasama dengan swasta dengan tempat usaha berupa toko, kios, los, dan tenda yang dimiliki/dikelola oleh 
pedagang kecil, menengah, swadaya masyarakat atau koperasi dengan usaha skala kecil, modal kecil, dan dengan proses jual beli barang dagangan melalui tawar menawar.

\subsection{Persyaratan Pasar Rakyat}

Menurut SNI 8152-2015, Pasar Rakyat harus memenuhi persyaratan sebagai berikut:

(1) Lokasi pasar harus memenuhi persyaratan sebagai berikut: a) Setiap lokasi pasar harus mempunyai bukti dokumen kepemilikan yang sah. b) Lokasi pasar sesuai dengan rencana tata ruang wilayah setempat.

(2) Untuk pembangunan pasar di lokasi yang baru, terdapat persyaratan lokasi yang harus dipenuhi yaitu: a) Jalan menuju pasar mudah diakses dan didukung dengan transportasi umum sehingga menjamin kelancaran kegiatan bongkar muat dan distribusi. b) Terletak di daerah yang aman dari banjir dan longsor. c) Jauh dari fasilitas yang berpotensi membahayakan, seperti pabrik atau gudang bahan kimia berbahaya, Stasiun Pengisian Bahan Bakar Umum (SPBU) atau tempat pembuangan sampah/limbah kimia dengan jarak minimal $10 \mathrm{~m}$. d) Tidak terletak pada bekas tempat pembuangan sampah atau bekas pabrik bahan kimia.

(3) Keamanan dan kenyamanan yang ada di pasar rakyat harus memenuhi persyaratan sebagai berikut: a) Penataan sirkulasi yang memudahkan pengunjung dapat bergerak dengan leluasa. b) Bahan bangunan hendaknya berupa bahan yang memudahkan perawatan.

(4) Ruang dagang terdiri atas toko/kios, los dan jongko/konter/pelataran harus memenuhi persyaratan sebagai berikut: a) Toko/kios dibuat tidak menutupi arah angin. b) Los harus dibuat modular. c) Jongko/konter/pelataran berada pada area yang sudah ditentukan yang tidak mengganggu akses keluar masuk pasar dan tidak menutupi pandangan toko/kios atau los.

(5) Aksesibilitas harus memenuhi persyaratan sebagai berikut: a) Seluruh fasilitas harus bisa diakses dan dimanfaatkan oleh semua orang, termasuk penyandang cacat, dan lansia. b) Akses kendaraan bongkar muat barang, harus berada di lokasi yang tidak menimbulkan kemacetan. c) Pintu masuk dan sirkulasi harus disediakan untuk menjamin ketercapaian semua fasilitas di dalam pasar, baik ruang dagang maupun fasilitas umum, termasuk untuk menanggulangi bahaya kebakaran.

(6) Penataan zonasi harus memenuhi persyaratan sebagai berikut: a) Dikelompokkan secara terpisah untuk bahan pangan basah, bahan pangan kering, siap saji, non pangan, dan tempat pemotongan unggas hidup. b) Memiliki jalur yang mudah diakses untuk seluruh konsumen dan tidak menimbulkan penumpukan orang pada satu lokasi tertentu. c) Tersedia papan nama yang menunjukkan keterangan lokasi zonasi.

\section{Metode}

\subsection{Karakteristik Desa Bulucindea Kec. Bungoro Kab. Pangkep}

Lokasi pengamatan pada pengabdian masyarakat ini yaitu Desa Bulucindea yang merupakan salah satu desa yang berada di Kecamatan Bungoro Kabupaten Pangkep. Letak geografis Desa Bulucindea adalah:

$\begin{array}{ll}\text { Sebelah Utara } & \text { : Kecamatan Labbakkang } \\ \text { Sebelah Timur } & \text { : Kelurahan Liukang Tupabiring }\end{array}$ 
Sebelah Selatan : Kelurahan Bori Apakka

Sebelah Barat : Desa Bowong Cindea
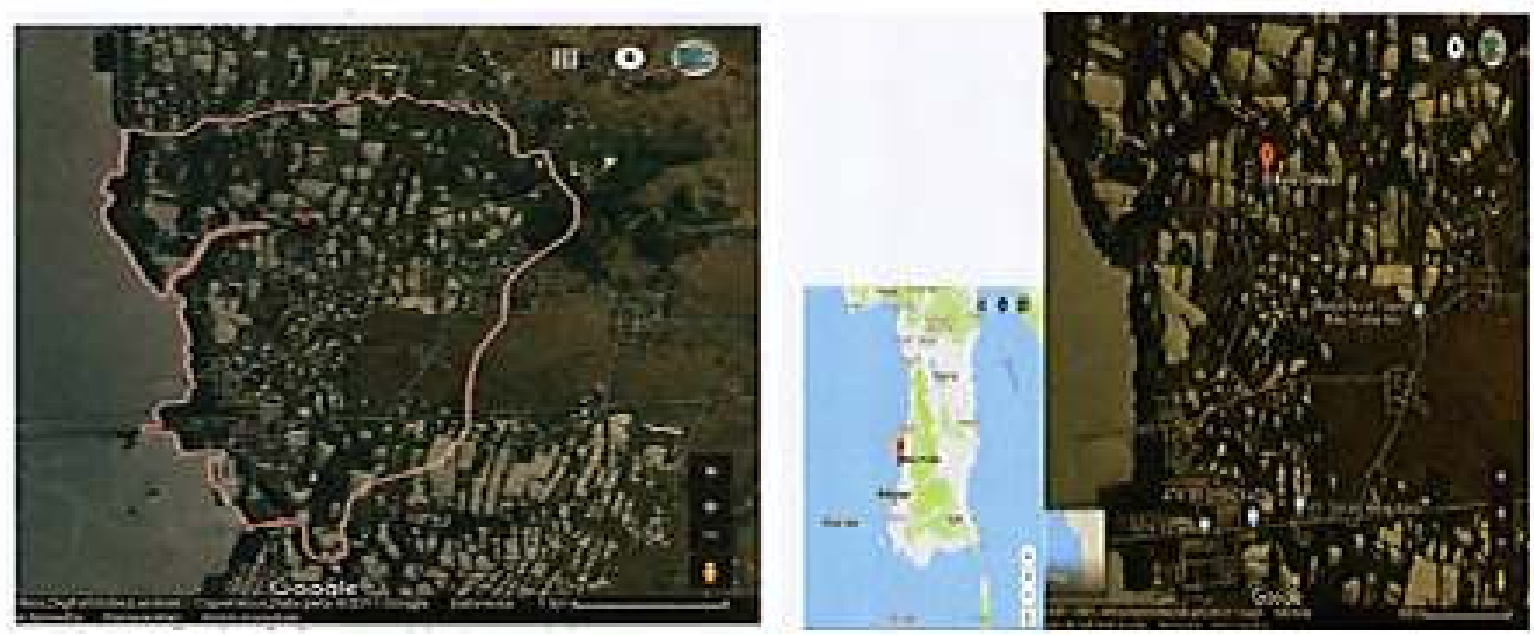

Gambar 1. Lokasi perencanaan pasar terapung Desa Bulucindea Kec. Bungoro Kab. Pangkep. (Sumber: Kec. Bungoro 2018).

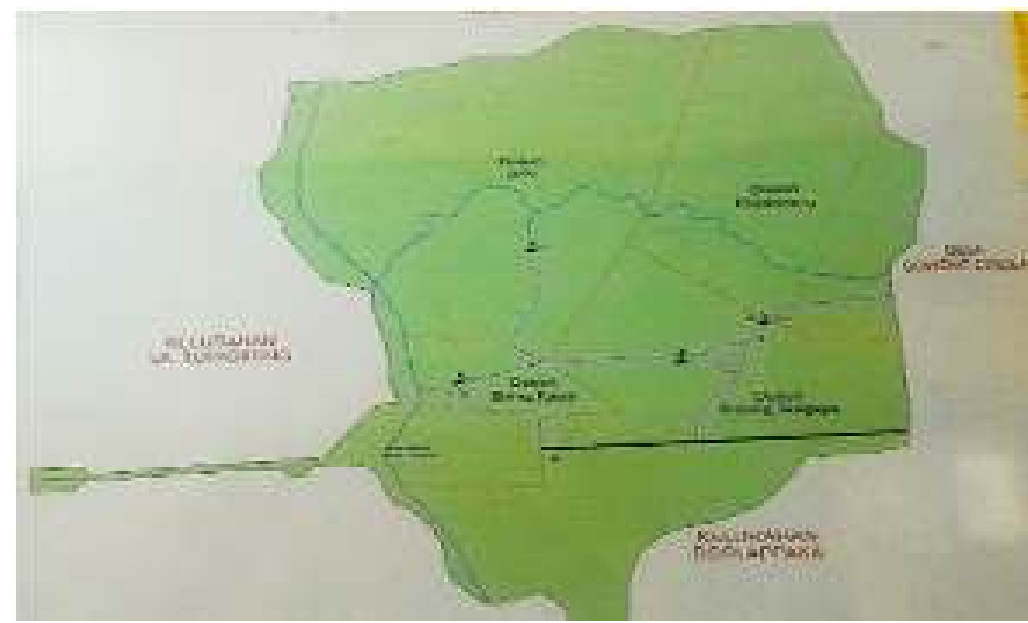

Gambar 2. Peta Desa Bulucindea (Sumber: Desa Bulucindea, 2018)

Secara administrasi Desa Bulucindea Kecamatan Bungoro Kabupaten Pangkep, statistik kota Makassar (Kecamatan Bungoro tahun 2018):

(1) Luas wilayahnya sekitar $7 \mathrm{~km}^{2}$ dan ketinggian dari permukaan laut $<500 \mathrm{~m}$

(2) Kecamatan Bungoro terdiri dari 4 Desa, 8 Rukun Warga (RW) dan setiap desa memiliki 2 RW, setiap RW terdapat 2 RT

(3) Jumlah rumah tangga di Desa Bulucindea adalah $1521 \mathrm{KK}$, dengan jumlah penduduk sebesar 5.192 jiwa.

\subsection{Perencanaan Pasar Tradisional Terapung}

Untuk mengetahui keterlibatan masyarakat dalam kegiatan perencanaan pasar tradisional terapung tersebut yakni penilaian masyarakat terhadap kebutuhan masyarakatnya terhadap sistem sarana dan prasarana lingkungan permukiman di wilayah/kawasan pesisir pantai. Dalam 
merumuskan kebutuhan akan sarana dan prasarana lingkungan permukiman di wilayah pesisir pantai Desa Bulucindea Kecamatan Bungoro Kabupatendan Kepualauan diperlukan masukkan atau saran dari masyarakat dan aparat, tokoh masyarakat terhadap permasalahan yang mengarah pada perencanaan pasar tradisional tersebut, yang berupa urutan prioritas pemenuhan kebutuhan terhadap perencanaan sistem sarana dan prasarana lingkungan permukiman seperti pasar tradisional dengan kondisi terapung di atas air. Untuk menampung aspirasi masyarakat di Desa Bulucindea, ada dua hal yang dilakukan, yaitu:

(1) Pencarian data untuk memenuhi kebutuhan masyarakat akan sistem sarana dan prasarana lingkungan permukiman terhadap keberadaan pasar tradisional terapung.

(2) Focus Group Discussion (FGD) dengan masyarakat dan tokoh masyarakat Desa Bulucindea Kecamatan Bungoro Kabupaten Pangkep dimaksudkan untuk menyusun urutan prioritas kebutuhan masyarakat terhadap pasar tradisional terapung.

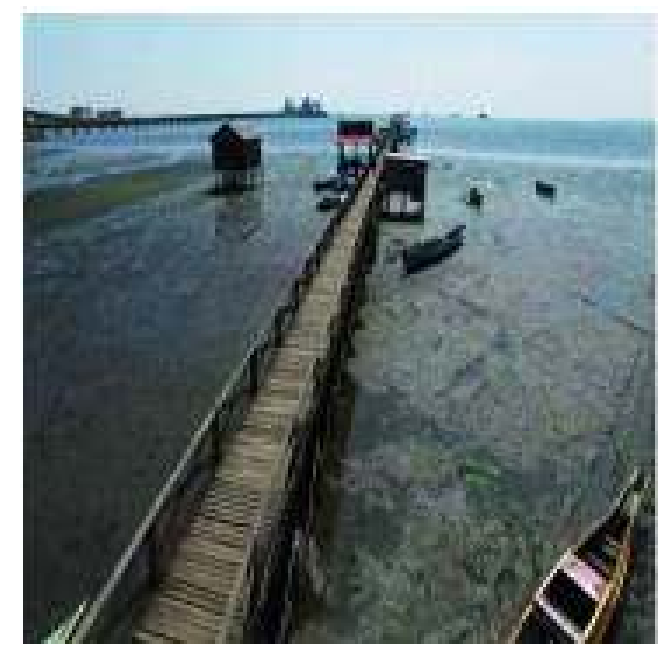

Gambar 3. Dermaga kawasan wisata di Desa Bulucindea

Gambar 3 menunjukkan rona awal kondisi dermaga dan pasar tradisional yang ada di Desa Bulucindea. Tahap identifikasi wilayah menunjukkan beberapa kawasan membutuhkan penataan kembali. Melalui penggalian masalah dan analisis lokasi, dilakukan FGD dengan masyarakat dan tokoh masyarakat setempat sebagai informan dan input untuk kegiatan perencanaan. Hasil perencanaan disosialisasikan ke masyarakat sehingga kegiatan ekonomi masyarakat dapat diwadahi tanpa merusak habitat alami lingkungan setempat. Proses pelaksanaan kegiatan pengbadian dapat dilihat di Gambar 4. 


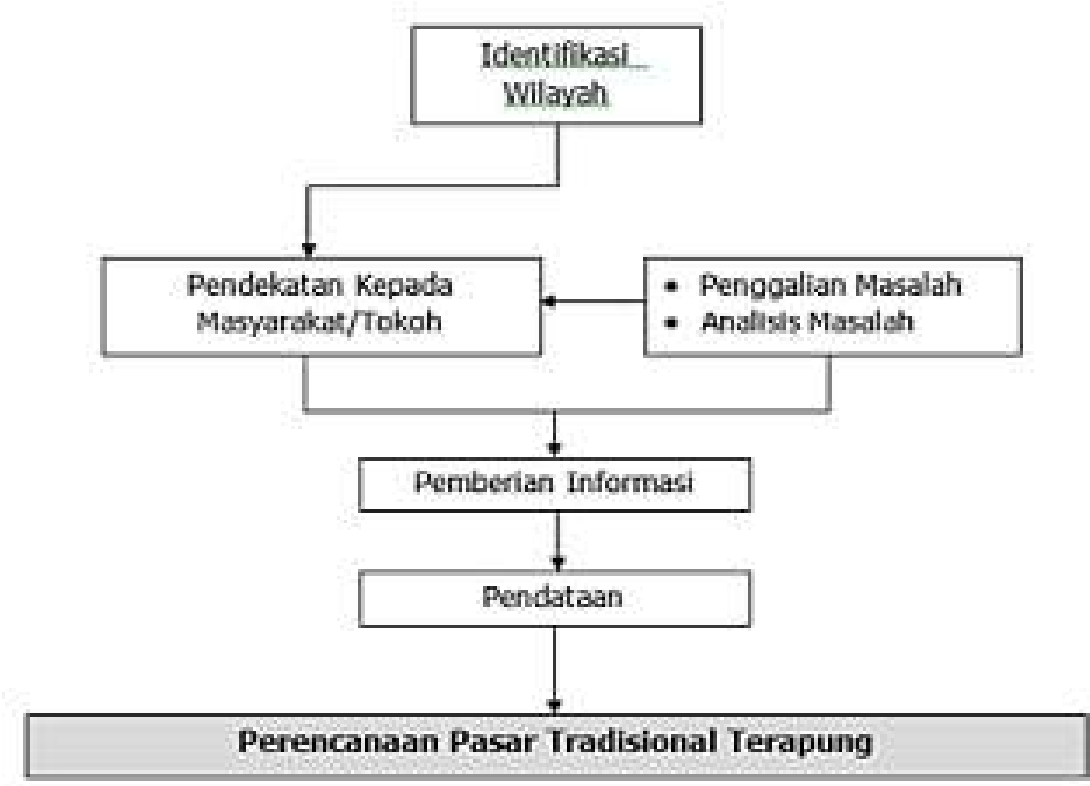

Gambar 4. Skema Pelaksanaan Kegiatan Pengabdian Kepada Masyarakat

\subsection{Metode Partisipasi}

Dalam proses partisipasi masyarakat dapat dilakukan, pertama adalah pemberdayaan primer dimana masyarakat diberi wewenang untuk memberikan saran kepada pihak yang perencana atau pelaksanaan partisipasi masyarakat dalam meningkatkan kesejahterannya. Kedua adalah pemberdayaan sekunder, dalam hal ini masyarakat diberi stimulan berupa pengarahan agar masyarakat dapat memahami dan mengerti akan kegiatan masyarakat yang bekerjasama dengan pihak-pihak terkait.

Model partisipasi masyarakat yang diterapkan pada kegiatan ini adalah pemberdayaan primer yaitu dengan mengadakan pendekatan langsung kepada masyarakat yang merupakan responden langsung kemudian menyebarkan kuesioner mengenai kebutuhan akan pasar tradisional terapung. Awalnya masyarakat menyampaikan kebutuhannya pada system sarana dan prasarana lingkungan permukiman yakni pasar tradisional yang disesuaikan dengan kondisi fisik lingkungan permukiman di Desa Bulucindea Kecamatan Bungoro Kabupaten Pangkep.

\section{Hasil dan Diskusi}

Standar perencanaan pasar tradisional terapung di Desa Bulucindea Kecamatan Bungoro Kabupaten Pangkep, memilik dasar standar perencanaan yang disesuaikan dengan SNI 81522015 dan SNI 03-1733-2004, yakni:

(1) Pola penataan pasar tradisional sedapat mungkin teratur, bangunan sejajar dengan arah penjalaran gelombang pasang dan tsunami atau tegak lurus dengan garis pantai agar air gelombang pasang mempunyai ruang dan tekanan air yang relatif kecil.

(2) Orientasi bangunan berkaitan dengan bentuk bangunan, sebab bentuk bangunan mempengaruhi besarnya tekanan angin.

(3) Bangunan dibuat sejajar dengan penjalaran gelombang pasang/tsunami atau tegak lurus terhadap garis pantai, agar tekanan air dan angin yang menghantam bangunan lebih kecil. 
(4) Sisi lebar bangunan dibuat sejajar dengan garis pantai sehingga mengurangi tekanan air (gelombang pasang, tsunami) dan angin (angin musim) menerpa bangunan.

(5) Penempatan bangunan pasar sebaiknya berada di atas air yang memiliki ketinggian minimal 1 meter (dpl).

(6) Penempatan bangunan pasar sebaiknya dekat dengan vegetasi alam, bangunan terlindungi dari hembusan gelombang air dan angin.

(7) Bangunan dapat diakses dengan mudah keluar masuk ke pasar tradisional terapung.
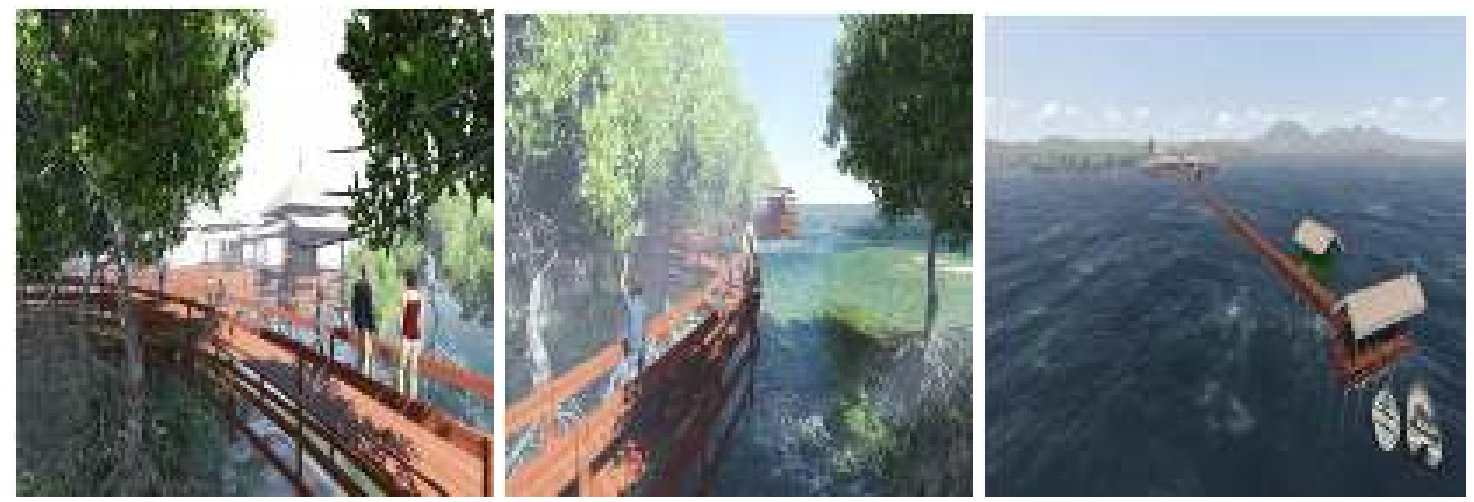

Gambar 5. Perencanaan jalan selasar pasar tradisional terapung di Desa Bulucindea
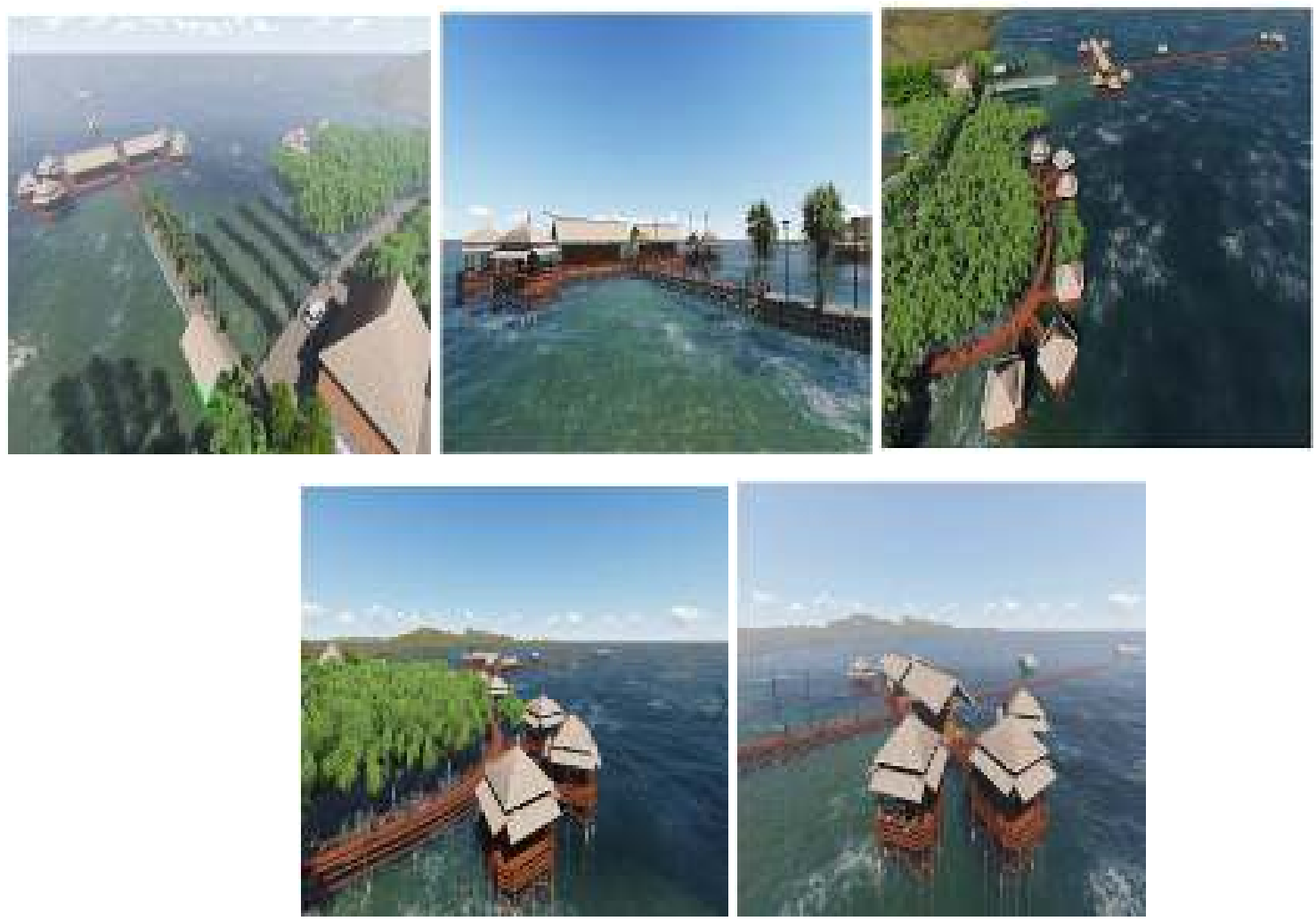

Gambar 6. Perencanaan pasar tradisional terapung Desa Bulucindea 

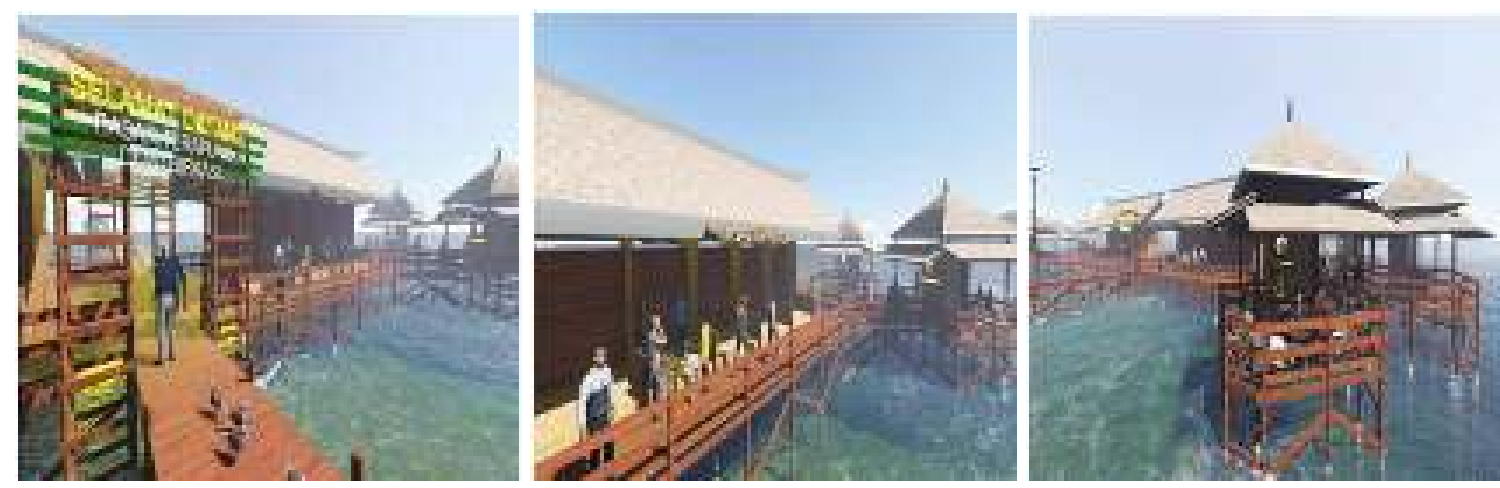

Gambar 7. Perencanaan pasar tradisional terapung Desa Bulucindea.

Kegiatan pengabdian masyarakat ini telah dilaksanakan dengan hasil sebagai berikut:

(1) Prioritas kebutuhan akan fasilitas sarana dan prasarana pasar tradisional terapung di kawasan pesisir Desa Bulucindea Kecamatan Bungoro Kabupaten Pangkep, sesuai SNI 8152-2015 dan SNI 03-1733-2004.

(2) Pola pemberdayaan masyarakat di Desa Bulucindea Kecamatan Bungoro Kabupaten Pangkep untuk mendukung perencanaan pasar tradisional terapung, diadakan:

- Pendekatan kepada tokoh masyarakat dan aparat pemerintah setempat untuk mendapatkan data-data kependudukan, sehingga data tersebut dapat diolah/dianalisis untuk memperoleh hasil yang maksimal dalam pengumpulan data-data primer dan sekunder.

- Sosialisasi kepada masyarakat pemakai pasar tradisional Desa Bulucindea Kecamatan Bungoro Kabupatendan Kepulauan bertujuan untuk mendapatkan data-data sekunder terkait perencanaan pasar tradisional terapung.

- Wawancara langsung sekaligus melihat langsung kegiatan transaksi ekonomi dalam hal pembelian dan penjualan bahan kebutuhan masyarakat.

- Pendampingan tokoh-tokoh masyarakat sebagai penggerak partisipasi masyarakat dalam bentuk pemberian informasi untuk kebutuhan pengadaan pasar tradisional terapung.

(3) Tahap sosialisasi dilaksanakan dalam waktu yang relatif singkat antara tim pelaksana program pengabdian masyarakat, dengan pihak terkait (pemerintah daerah) dan masyarakat Desa Bulucindea Kecamatan Bungoro Kabupaten Pangkep.

(4) Berdasarkan observasi lokasi, maka dilakukan identifikasi masalah di lahan perencanaan pasar tradisional terapung terhadap fasilitas perdagangan yang dibutuhkan masyarakat, selanjutnya hasil dari identifikasi tersebut berupa peta lokasi, serta gambar perencanaan pasar tersebut.

(5) Bentuk implementasi perencanaan pasar tradisional terapung Desa Bulucindea Kecamatan Bungoro Kabupaten Pangkep sangat dipengaruhi dengan adanya :

- Aktivitas perdagangan berupa penjualan dan pembelian secara tradisional memberikan masukan/input dalam perencanaan pasar tradisional terapung di lingkungan tersebut.

- Peran aktif aparat setempat yang memberikan data-data sekunder dan aparat setempat untuk kebutuhan perencanaan pasar tradisional terapung.

- Adanya pedoman teknis tentang pedoman perencanaan sarana dan prasarana khususnya pasar tradisional terapung di lingkungan pemukiman pesisir pantai sesuai SNI 03-17332004. 


\section{Kesimpulan}

Kebutuhan pasar tradisional terapung disesuaikan dengan pedoman perencanaan sarana dan prasarana di lingkungan pesisir pantai. Mengingat kebutuhan masyarakat akan kegiatan ekonomi di wilayah pesisir, maka perencanaan pasar tradisional disesuaikan dengan kondisi lingkungan dan matapencarian masyarakat setempat. Perencanaan pasar tradisional terapung memberikan kontribusi bagi peningkatan ekonomi masyarakat dan kualitas lingkungan di kawasan wisata mangrove Desa Bulucindea Kecamatan Bungoro Kabupaten Pangkep. Perencanaan tersebut selain memberikan wadah bagi kegiatan ekonomi masyarakat, juga melibatkan masyarakat dalam menjaga keberlanjutan kawasan mangrove.

\section{Ucapan Terima Kasih}

Ucapan terima kasih kepada Fakultas Teknik Universitas Hasanuddin atas pendanaan kegiatan pengabdian masyarakat (LBE), dan Kepala Desa Bulucindea Kecamatan Bungoro Kabupaten Pangkep, yang telah memfasilitasi pelaksanaan serta mendorong keaktifan masyarakat dalam kegiatan pengabdian ini.

\section{Daftar Pustaka}

PERPRES No. 112 Tahun 2007, Tentang Penataan dan Pembinaan Pasar Tradisional.

Badan Standardisasi Nasional SNI 8152-2015, Pasar Rakyat.

Badan Standardisasi Nasional SNI 03-1733-2004, Tata Cara Perencanaan Lingkungan. 